\title{
PENGARUH PRODUKTIVITAS TENAGA KERJA TERHADAP KINERJA WAKTU PROYEK PADA BANGUNAN BERTINGKAT
}

\author{
(The Effect of Labor Productivity in Time Project Performance at High Rise Building) \\ Indah Prasetiya Rini ${ }^{1}$ \\ ${ }^{1}$ Program Studi Teknik Sipil Universitas Gunadarma \\ E-mail: indah prasetiya@staff.gunadarma.ac.id
}

\begin{abstract}
ABSTRAK
Setiap proyek konstruksi membutuhkan sumber daya (resources) dalam penyelesaiannya, yaitu pekerja, biaya, alat, metode, dan material. Dalam proses mencapai tujuan proyek, telah ditentukan batasan yang dikenal dengan tiga kendala (triple constraint), yaitu besar biaya (anggaran) yang dialokasikan, jadwal, dan mutu yang harus dipenuhi. Dengan melihat batasan (triple constraint) yang ditentukan dalam proyek, produktivitas tenaga kerja merupakan salah satu faktor penting yang berpengaruh terhadap kinerja waktu proyek. Tujuan dari penelitian ini adalah untuk menganalisis pengaruh produktivitas tenaga kerja terhadap kinerja waktu proyek pada bangunan bertingkat khususnya di daerah Jabodetabek. Jenis data yang digunakan dalam penelitian ini adalah data primer, sedangkan untuk teknik analisis data dalam penelitian ini adalah regresi linear sederhana dengan menggunakan perangkat lunak SPSS v.24. Dari hasil penelitian didapatkan hasil bahwa produktivitas tenaga kerja berpengaruh secara signifikan terhadap kinerja waktu proyek. Dengan kata lain, jika semakin tinggi produktivitas tenaga kerja, maka semakin singkat pula waktu yang diperlukan dalam penyelesaian suatu kegiatan, begitupun sebaliknya.
\end{abstract}

Kata Kunci: produktivitas tenaga kerja, kinerja waktu proyek, analisis regresi

\begin{abstract}
In construction of each project requires resources in its completion. They are workers, costs, tools, methods, and materials. The process for achieving project purpose, have defined the boundary called triple constraints, are budget allocated, schedule, and quality. From these (triple constraint) in the project, productivity of labors are one of an important thing that give an effect in time project performance. This research is to analyze the effect of labor productivity in time project performance at high rise building, especially in Jabodetabek area. The type of data for this research use primary data, and for data analysis technique use a simple linear regression with SPSs v.24 as a software. The result is labor productivity give the effect significantly in time project performance. In other words, if the labor productivity higher than the time to complete all activities will be shorter, and vice versa.
\end{abstract}

Keywords: labor productivity, time project performance, regression analysis. 


\section{PENDAHULUAN}

Proyek konstruksi merupakan suatu rangkaian kegiatan yang hanya satu kali dilaksanakan, dan umumya berjangka waktu pendek. Dalam rangkaian kegiatan tersebut, terdapat suatu proses yang mengolah sumber daya proyek menjadi suatu hasil kegiatan yang berupa bangunan. Proses yang terjadi dalam rangkaian kegiatan tersebut tentunya melibatkan pihak-pihak yang terkait, baik secara langsung maupun tidak langsung (Wulfram, 2005).

Kegiatan proyek dapat diartikan sebagai suatu kegiatan sementara yang berlangsung dalam jangka waktu terbatas, dengan alokasi sumber daya tertentu dan dimaksudkan untuk melaksanakan tugas yang sasarannya telah digariskan dengan jelas (Soeharto, 1997).

Timbulnya proyek berasal dari beberapa sumber, yaitu rencana pemerintah, permintaan pasar, dari dalam perusahaan yang bersangkutan dan dari kegiatan penelitian atau pengembangan. Bagi proyek yang berukuran besar dan kompleks, karena umumnya melibatkan sumber daya yang besar, prakarsa sering timbul dari pihak pemerintah, perusahaan swasta besar atau multinasional.

Menurut Soeharto (1997), proyek konstruksi memiliki ciri-ciri pokok, yaitu:

1. Memiliki tujuan yang khusus, produk akhir atau hasil kerja akhir.

2. Jumlah biaya, sasaran jadwal serta kriteria mutu dalam proses mencapai tujuan yang telah ditentukan.

3. Bersifat sementara, dalam arti umumnya dibatasi oleh selesainya tugas. Titik awal dan akhir ditentukan dengan jelas.

4. Nonruitn, tidak berulang-ulang. Jenis dan intensitas kegiatan berubah sepanjang proyek berlangsung.

Suatu rangkaian kegiatan dalam proyek konstruksi dapat dibedakan atas dua jenis, yaitu kegiatan rutin dan kegiatan proyek. Kegiatan rutin adalah suatu rangkaian kegiatan terus menerus yang berulang dan berlangsung lama, sedangkan kegiatan proyek adalah suatu rangkaian kegiatan yang hanya satu kali dilaksanakan dan umunya berlangsung dalam jangka waktu yang pendek (Wulfram, 2005). Karakteristik proyek konstruksi menurut Wulfram (2005), dapat dipandang dalam tiga dimensi, yaitu:

1. Proyek bersifat unik, artinya tidak pernah terjadi rangkaian kegiatan yang sama percis (tidak ada proyek identik, yang ada adalah proyek sejenis), proyek bersifat sementara dan selalu melibatkan kelompok pekerja yang berbeda-beda.

2. Membutuhkan sumber daya (resources), artinya setiap proyek konstruksi membutuhkan sumber daya dalam penyelesaiannya, yaitu pekerja, cost, peralatan, metode dan material. Pengorganisasian semua sumber daya tersebut dilakukan oleh manajer proyek.
3. Membutuhkan organisasi, artinya setiap organisasi mempunyai keragaman tujuan, dimana di dalamnya terlibat sejumlah individu dengan rangam keahlian ketertarikan, kepribadian dan juga ketidakpastian. Menyatukan visi menjadi suatu tujuan yang telah ditetapkan oleh organisasi merupakan langkah awal yang harus dilakukan oleh seorang manajer proyek.

Komponen kegiatan utama dalam proyek konstruksi terdiri dari pengkajian kelayakan, desain engineering, pengadaan, dan konstruksi. Sehingga proyek konstruksi dapat dibedakan menjadi dua jenis kelompok bangunan, yaitu:

1. Bangunan gedung: rumah, kantor, pabrik, dan lain-lain. Ciri-ciri dari kelompok bangunan ini adalah:

a. Proyek konstruksi menghasilkan tempat orang bekerja atau tinggal.

b. Pekerjaan dilaksanakan pada lokasi yang relatif sempit dan kondisi pondasi umumnya sudah diketahui.

c. Manajemen dibutuhkan, terutama untuk progressing pekerjaan.

2. Bangunan sipil: jalan, jembatan, bendungan, dan infrastruktur lainnya. Ciri-ciri dari kelompok bangunan ini adalah:

a. Proyek konstruksi dilaksanakan untuk mengendalikan alam agar berguna bagi kepentingan manusia.

b. Pekerjaan dilaksanakan pada lokasi yang luas atau panjang dan kondisi pondasi sangat berbeda satu sama lain dalam suatu proyek.

c. Manajemen dibutuhkan untuk memecahkan permasalahan.

Kedua kelompok bangunan tersebut sebenarnya saling tumpang tindih, tetapi pada umumnya direncanakan dan dilaksanakan oleh disiplin ilmu perencana dan pelaksana yang berbeda.

Dalam setiap proyek memiliki tujuan khusus, misalnya rumah tinggal, jembatan, atau instalasi pabrik, dapat pula berupa produk hasil kerja penelitian dan pegembangan. Di dalam proses mencapai tujuan tersebut, telah ditentukan batasan, yaitu besar biaya (anggaran) yang dialokasikan, jadwal dan mutu yang harus dipenuhi. Ketiga batasan tersebut dinamakan tiga kendala (triple constraint). Tiga kendala tersebut merupakan parameter penting bagi penyelenggaraan proyek yang sering diasosiasikan sebagai sasaran proyek. Ketiga batasan tersebut saling tarik-menarik, artinya jika ingin meningkatkan kinerja produk yang telah disepakati dalam kontrak, maka umumnya diikuti dengan menaikkan mutu, yang selanjutnya berakibat pada naiknya biaya melebihi anggaran. Sebaliknya, bila ingin menekan biaya, maka biasanya harus berkompromi dengan mutu atau jadwal. Dari segi teknis, ukuran keberhasilan proyek dikaitkan dengan sejauh mana ketiga sasaran tersebut dapat dipenuhi (Soeharto, 1997). 
Sumber daya proyek konstruksi merupakan kemampuan dan kapasitas potensi yang dapat dimanfaatkan untuk kegiatan konstruksi. Sumber daya diperlukan guna melaksanakan pekerjaan-pekerjaan yang merupakan komponen-komponen proyek. Hal tersebut dilakukan terkait dengan ketepatan perhitungan unsur biaya, mutu dan waktu (Muzayanah, 2008). Pengelolaan sumber daya proyek perlu dilakukan secara tepat agar ketiga batasan proyek (triple constraint) dapat dipenuhi (tepat biaya, tepat mutu dan tepat waktu). Secara umum, sumber daya proyek konstruksi terdiri dari sumber daya biaya, waktu manusia, material, peralatan, metode konstruksi, dan teknologi.

Dalam penyelenggaraan proyek konstruksi salah satu sumber daya yang menjadi faktor penentu keberhasilan proyek konstruksi adalah sumber daya manusia (tenaga ahli, tenaga terampil dan tenaga non skill). Berdasarkan Pedoman Peningkatan Profesionalitas SDM Konstruksi (2007), sumber daya manusia terdiri dari:

1. Tenaga kerja konstruksi, merupakan porsi terbesar dari proyek konstruksi. Sumber daya manusia konstruksi adalah pelaku pekerjaan di bidang konstruksi yang terdiri dari perencana, pelaksana dan pengawas, dimana sumber daya manusia konstruksi mencakup:

a. Pekerja yang mencakup pekerja tidak terampil, pekerja semi terampil dan pekerja terampil.

b. Teknisi terampil yang mencakup teknisi terampil administrasi dan teknisi terampil teknis.

c. Teknisi ahli dan teknisi profesional.

d. Tenaga manajerial yang bisa dikelompokkan menjadi manajerial terampil dan tenaga manajerial ahli.

e. Tenaga profesional.

2. Dilihat dari tingkat pendidikannya, struktur sumber daya manusia konstruksi pada umunya terdiri dari:
a. Pekerja: SD, SLTP.
b. Teknisi terampil: SMU.
c. Teknisi ahli: D3 atau S1
d. Tenaga manajerial terampil: SMU, tenaga manajerial ahli D3 atau S1
e. Tenaga profesional: S2 dan S3.

Sedangkan menurut Soeharto (1997), tenaga kerja konstruksi dapat digolongkan menjadi dua macam, yaitu penyelia atau pengawas dan pekerja atau buruh lapangan (craft labor). Dilihat dari bentuk hubungan kerja antara pihak yang bersangkutan, maka tenaga kerja proyek khususnya tenaga kerja konstruksi dibedakan menjadi:

1. Tenaga kerja langsung (direct hire), yaitu tenaga kerja yang direkrut dan menandatangani ikatan kerja perseorangan dengan perusahaan kontraktor. Umumnya diikuti dengan latihan sampai dianggap cukup memiliki pengetahuan dan kecakapan dasar.
2. Tenaga kerja borongan, yaitu tenaga kerja yang bekerja berdasarkan ikatan kerja yang ada antara perusahaan penyedia tenaga kerja (labor supplier) dengan kontraktor untuk jangka waktu tertentu.

Salah satu batasan dalam proyek agar tujuan proyek dapat terpenuhi adalah batasan waktu. Waktu atau jadwal merupakan salah satu sasaran utama proyek. Keterlambatan akan mengakibatkan berbagai bentuk kerugian, misalnya penambahan biaya, kehilangan kesempatan produk memasuki pasaran, dan lain-lain. Proyek harus dikerjakan sesuai dengan kurun waktu dan tanggal akhir yang telah ditentukan (Soeharto, 1997). Banyak faktor yang mungkin berpengaruh terhadap kinerja waktu proyek, misalkan produktivitas tenaga kerja.

Suatu perencanaan tenaga kerja proyek yang menyeluruh dan terinci harus meliputi perkiraan jenis dan kapan keperluan tenaga kerja, seperti tenaga ahli dari berbagai disiplin ilmu pada tahap desain engineering dan pembelian, supervisor dan pekerja lapangan untuk pabrikasi dan konstruksi. Dengan mengetahui perkiraan angka dan jadwal kebutuhannya, maka dapat dimulai kegiatan pengumpulan informasi perihal sumber penyediaan baik kuantitas maupun kualitas. Perencanaan sumber daya manusia pada proyek diawali dengan memperkirakan jumlah tenaga kerja yang diperlukan. Untuk itu, diperlukan parameter penting, yaitu produktivitas tenaga kerja yang merupakan faktor utama yang mempengaruhi jumlah tenaga kerja. Dengan kata lain, jika produktivitas tenaga kerja semakin tinggi, maka jumlah tenaga kerja menjadi lebih sedikit, begitu juga sebaliknya. Oleh karena itu, penting sekali menjaga produktivitas tenaga kerja untuk tidak menurun. Salah satu caranya adalah dengan mengetahui faktor-faktor apa saja yang mempengaruhi produktivitas tenaga kerja, seperti yang dilakukan pada penelitian ini, yaitu menganalisis pengaruh produktivitas tenaga kerja terhadap kinerja waktu proyek.

Produktivitas didefinisikan sebagai rasio antara output dengan input, atau rasio antara hasil produksi dengan total sumber daya yang digunakan. Dalam proyek konstruksi, rasio produktivitas adalah nilai yang diukur selama proyek konstruksi, dapat dipisahkan menjadi biaya tenaga kerja, material, uang, metode, dan alat. Sukses dan tidaknya proyek konstruksi tergantung pada efektifitas pengelolaan sumber daya (Wulfram, 2005). Pekerja adalah satu sumber daya yang tidak mudah dikelola. Banyak faktor yang mempengaruhi tingkat produktivitas para pekerja.

Mengingat pada umumnya proyek berlangsung dengan kondisi yang berbeda-beda, maka dalam merencanakan tenaga kerja hendaknya dilengkapi dengan analisis produktivitas dan indikasi variabel yang mempengaruhi. Variabel atau faktor ini misalnya disebabkan oleh lokasi geografis proyek, iklim, 
keterampilan, pengalaman ataupun oleh peraturanperaturan yang berlaku (Soeharto, 1997).

Melihat pentingnya faktor tenaga kerja dalam kinerja waktu proyek, maka tujuan dari penelitian ini adalah untuk menganalisis pengaruh produktivitas tenaga kerja terhadap kinerja waktu proyek pada bangunan bertingkat khususnya di daerah Jabodetabek.

\section{METODE}

Proses penelitian dimulai dari menentukan tujuan terlebih dahulu, yaitu untuk menganalisis pengaruh produktivitas tenaga kerja terhadap kinerja waktu proyek pada bagunan bertingkat. Kemudian dilakukan pengumpulan data yang selanjutnya akan diproses dengan bantuan perangkat lunak SPSS. Untuk lebih lengkapnya, proses penelitian dapat dilihat pada Gambar 1.

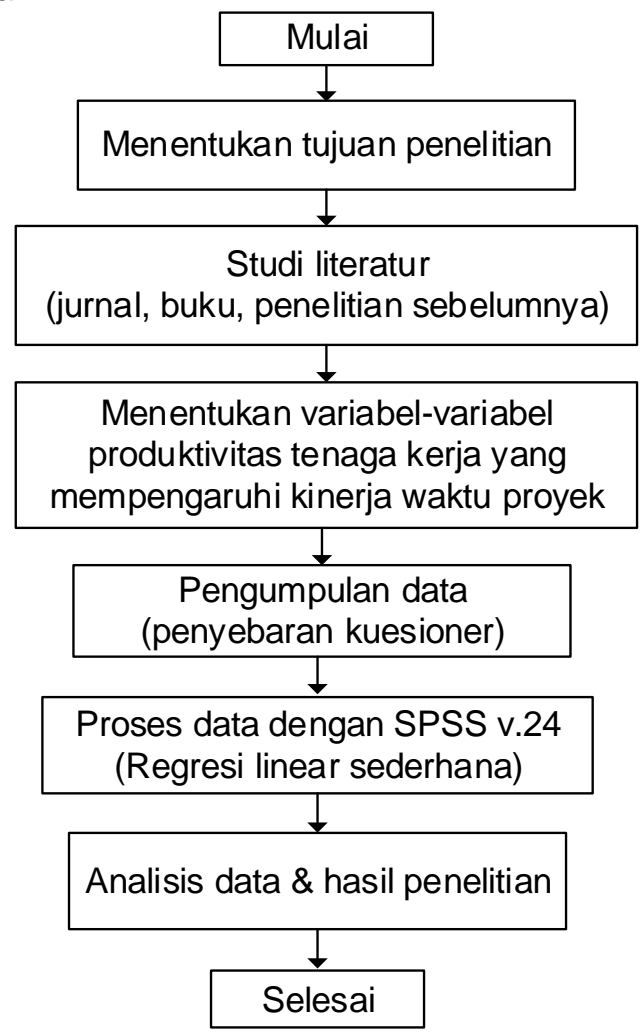

Gambar 1. Proses Penelitian

Jenis data yang digunakan dalam penelitian ini adalah data primer, yaitu dilakukan dengan cara penyebaran kuesioner kepada responden yang mempunyai pengalaman di bidang konstruksi, yaitu dengan mengidentifikasi tingkat pengaruh variabel produktivitas tenaga kerja terhadap kinerja waktu proyek dengan menggunakan skala ordinal (Tabel 3). Sampel yang digunakan hanya berpusat pada daerah Jabodetabek. Olah data dilakukan dengan bantuan perangkat lunak, yaitu SPSS v.24, sedangkan untuk proses datanya menggunakan teknik regresi linear sederhana.

\section{Variabel Penelitian}

Variabel bebas $(x)$ pada penelitian ini adalah faktorfaktor yang mempengaruhi produktivitas tenaga kerja terhadap kinerja waktu proyek pada saat pelaksanaan proyek konstruksi gedung. Faktor-faktor yang mempengaruhi produktivitas tenaga kerja pada proyek bangunan bertingkat dapat dilihat pada Tabel 1 . Variabel terikat $(y)$ pada penelitian ini merupakan kinerja waktu proyek yang terdiri dari beberapa tingkatan. Variabel terikat pada penelitian ini dapat dilihat pada Tabel 2.

Tabel 1. Variabel Bebas $(x)$

\begin{tabular}{l} 
Faktor yang Mempengaruhi Produktivitas Tenaga \\
Kerja terhadap Kinerja Waktu Proyek \\
\hline \hline Man Group Factor \\
x1: Kesalahpahaman diantara tenaga kerja \\
\hline Leadership Group Factor \\
x2: Kurangnya pengawasan tenaga kerja \\
x3: Kesalahpahaman diantara tenaga kerja dan \\
pengawas \\
x4: Kurangnya meeting/pertemuan dengan \\
tenaga kerja \\
\hline Time Group Factor \\
x5: Bekerja penuh selama satu minggu tanpa \\
hari libur \\
x6: Kerja lembur
\end{tabular}

\section{Materials/Tools Group Factor}

x7: Kurangnya ketersediaan material

$x 8$ : Kekurangan ketersediaan alat

x9: Lokasi penempatan material yang tidak strategis

\section{Supervision Group Factor}

x10: Keterlambatan inspeksi

$\mathrm{x} 11$ : Adanya pekerjaan ulang

x12: Ketidakhadiran supervisor

\section{Safety Group Factor}

x13: Kecelakaan kerja

$\mathrm{x} 14$ : Minimnya peralatan safety

x15: Sistem penghawaan yang buruk

Sumber: Adnan Enshassi dan kawan-kawan, 2007

Tabel 2. Variabel Terikat $(y)$

\begin{tabular}{|c|c|c|}
\hline Kriteria & Uraian & Nilai \\
\hline Sangat cepat & $\begin{array}{l}\text { Kinerja waktu sangat cepat } \\
(80 \% \text { dari jadwal) }\end{array}$ & 6 \\
\hline Cepat & $\begin{array}{l}\text { Kinerja waktu cepat }(90 \% \\
\text { dari jadwal) }\end{array}$ & 5 \\
\hline Cukup cepat & $\begin{array}{l}\text { Kinerja waktu cukup cepat } \\
(100 \% \text { dari jadwal) }\end{array}$ & 4 \\
\hline Agak lambat & $\begin{array}{l}\text { Kinerja waktu agak lambat } \\
(110 \% \text { dari jadwal }\end{array}$ & 3 \\
\hline Lambat & $\begin{array}{l}\text { Kinerja waktu lambat } \\
(120 \% \text { dari jadwal) }\end{array}$ & 2 \\
\hline Sangat lambat & $\begin{array}{l}\text { Kinerja waktu sangat } \\
\text { lambat }(130 \% \text { dari jadwal) }\end{array}$ & 1 \\
\hline
\end{tabular}


Sumber: Widayat, 2007

Tabel 3. Skala Tingkat Pengaruh (Severity)

\begin{tabular}{lc}
\hline \multicolumn{1}{c}{ Kriteria Kualitatif } & Nilai \\
\hline Sangat besar & 1 \\
Besar & 2 \\
Sedang & 3 \\
Kecil & 4 \\
Sangat kecil & 5 \\
\hline
\end{tabular}

Sumber: Riantini, 2005

\section{Analisis Validitas dan Reliabilitas}

Uji validitas dilakukan untuk mengetahui kesesuain data kuesioner yang dikumpulkan peneliti dari responden. Uji validitas yang dilakukan pada penelitian ini adalah dengan melihat nilai corrected item-total correlation, yaitu membandingkan angka $r$ hitung dengan $r$ tabel. Jika $r$ hitung lebih besar dari $r$ tabel maka item dikatakan valid, atau sebaliknya. Untuk nilai $r$ hitung digunakan dari hasil output program SPSS (nilai corrected item-total correlation), sedangkan nilai $r$ tabel dengan jumlah sampel sebanyak 33 didapatkan nilai $r$ tabel 0,334 .

Suatu instrumen pengukuran (misalnya kuesioner) dikatakan reliable bila memberikan hasil score yang konsisten pada setiap pengukuran. Suatu pengukuran mungkin reliabel tapi tidak valid, tetapi suatu pengukuran tidak bisa dikatakan valid bila tidak reliabel. Ini artinya, reliabilitas (reliability) merupakan syarat perlu tapi tidak cukup (necessary but not sufficient condition) untuk validitas. Analisis reliabilitas digunakan untuk:

1. Mengetahui bagaimana butir-butir pertanyaan dalam kuesioner saling berhubungan.

2. Mendapatkan nilai Alpha Cronbach yang merupakan indeks internal consistency dari skala pengukuran secara keseluruhan.

3. Mengidentifikasi butir-butir pertanyaan dalam kuesioner yang bermasalah dan harus direvisi atau harus dihilangkan.

Alpha Cronbach merupakan salah satu koefisien reliabilitas yang paling sering digunakan, begitu pun dalam penelitian ini juga menggunakan Alpha Cronbach sebagai koefisien reliabilitas. Skala pengukuran yang reliabel sebaiknya memiliki nilai Alpha Cronbach minimal 0,70 (Nunnally, 1978 dan Nunnally and Bernstein, 1994). Alpha Cronbach dapat diinterpretasikan sebagai korelasi dari skala yang diamati (observed scale) dengan semua kemungkinan pengukuran skala lain yang mengukur hal yang sama dan menggunakan jumlah butir pertanyaan yang sama (Uyanto, 2006). Rumus untuk korelasi Alpha Cronbach adalah sebagai berikut: $\alpha_{\text {Cronbach }}=\left(\frac{k}{k-1}\right)\left(1-\frac{\sum_{i=1}^{k} s_{i}^{2}}{s_{p}^{2}}\right)$

dimana:

$\mathrm{k}=$ jumlah butir dalam skala pengukuran

$s_{i}^{2}=$ ragam (variance) dari butir ke-i

$s_{p}{ }^{2}=$ ragam (variance) dari skor total

\section{Analisis Regresi}

Dalam analisis regresi, akan dikembangkan sebuah estimating equation (persamaan regresi), yaitu suatu formula yang mencari nilai variabel dependent (tergantung) dari nilai variabel independent (bebas) yang diketahui. Dari jumlah variabel independent yang dimasukkan, regresi bisa dibedakan antara regresi sederhana dan regresi berganda atau multiple regression (Santoso, 2005). Pada penelitian ini hanya terdapat satu variabel dependent (produktivitas tenaga kerja) dan satu variabel independent (kinerja waktu proyek), maka teknik analisis data dalam penelitiain ini menggunakan analisis regresi sederhana, dengan hipotesis adalah sebagai berikut:

\section{Hipotesis:}

$\mathrm{H}_{0}$ : Produktivitas tenaga kerja tidak berpengaruh terhadap kinerja waktu proyek

$\mathrm{H}_{1}$ : Produktivitas tenaga kerja berpengaruh terhadap kinerja waktu proyek

Analisis regresi sederhana digunakan untuk memprediksi nilai suatu variabel dependet berdasarkan nilai variabel-variabel lain. Analisis regresi juga dapat digunakan untuk melihat pengaruh variabel independent $x$ terhadap variabel dependent $y$. Variabel independent $x$ sering disebut sebagai variabel predictor, sedangkan variabel dependent $y$ sering disebut sebagai variabel response. Model regresi sederhana dapat dinyatakan sebagai persamaan linear adalah:

$y_{i}=\beta_{o}+\beta_{1} x_{i}+\varepsilon_{i}$

dimana $\beta_{0}$ dan $\beta_{1}$ adalah parameter dari model regresi. Untuk mengestimasi nilai $\beta_{0}$ dan $\beta_{1}$ digunakan metode kuadrat terkecil (least squares method) berdasarkan persamaan:

$y_{i}=b_{o}+b_{1} x_{i}$

dimana:

$\mathrm{Y}=$ variabel response atau variabel dependent (tergantung)

$\mathrm{x}_{\mathrm{i}}=$ variabel predictor atau faktor penyebab (independent)

$\mathrm{b}_{0}=$ konstanta

$b_{1}=$ koefisien regresi (kemiringan) atau besaran response yang ditimbulkan oleh predictor.

Dalam pengujian hipoesis, kriteria untuk menolak atau tidak menolak $\mathrm{H}_{0}$ berdasarkan $P-$ value adalah sebagai berikut:

Jika $P$ - value $<\alpha$, maka $\mathrm{H}_{0}$ ditolak 
Jika $P$ - value $\geq \alpha$, maka $\mathrm{H}_{0}$ tidak dapat ditolak

Dalam program SPSS digunakan istilah Significance (yang disingkat Sig.) untuk $P$ - value; dengan kata lain, $P-$ value $=$ Sig. (Uyanto, 2006) .

\section{HASIL DAN PEMBAHASAN}

Dari penyebaran kuesioner yang dilakukan, jumlah data yang diolah dalam penelitian ini adalah sebanyak 33 responden yang tersebar di beberapa perusahaan, baik jenis perusahaan pemerintah maupun swasta. Responden terdiri dari beberapa macam latar belakang pendidikan dan pengalaman di bidang konstruksi. Informasi tentang data umum proyek dan responden pada penelitian ini dapat dilihat pada Tabel 4 serta Gambar 2 dan Gambar 3.

Tabel 4. Data Umum Proyek

\begin{tabular}{|c|c|c|c|}
\hline No & Uraian Profil & $\begin{array}{l}\text { Jumlah } \\
\text { Sampel }\end{array}$ & Presentase \\
\hline 1 & $\begin{array}{l}\text { Jenis perusahaan: } \\
\text { a. Pemerintah } \\
\text { b. Swasta }\end{array}$ & $\begin{array}{l}14 \\
19\end{array}$ & $\begin{array}{l}42,4 \% \\
57,6 \% \\
\end{array}$ \\
\hline 2 & $\begin{array}{l}\text { Lokasi proyek: } \\
\text { a. Jakarta } \\
\text { b. Bogor } \\
\text { c. Depok } \\
\text { d. Tangerang }\end{array}$ & $\begin{array}{c}21 \\
4 \\
6 \\
2 \\
\end{array}$ & $\begin{array}{c}63,6 \% \\
12,1 \% \\
18,2 \% \\
6,1 \% \\
\end{array}$ \\
\hline 3 & $\begin{array}{l}\text { Jumlah lantai } \\
\text { a. } 5-8 \text { lantai } \\
\text { b. }>8 \text { lantai }\end{array}$ & $\begin{array}{l}13 \\
20 \\
\end{array}$ & $\begin{array}{l}39,4 \% \\
60,6 \% \\
\end{array}$ \\
\hline 4 & $\begin{array}{l}\text { Waktu pelaksanaan } \\
\text { proyek: } \\
\text { a. < } 6 \text { bulan } \\
\text { b. } 6-12 \text { bulan } \\
\text { c. }>12 \text { bulan } \\
\text { d. Tidak } \\
\text { diketahui }\end{array}$ & $\begin{array}{c}5 \\
15 \\
11 \\
2\end{array}$ & $\begin{array}{c}15,2 \% \\
45,5 \% \\
33,3 \% \\
6,1 \%\end{array}$ \\
\hline
\end{tabular}

Sumber: Pengumpulan data primer

Tingkat Pendidikan Responden

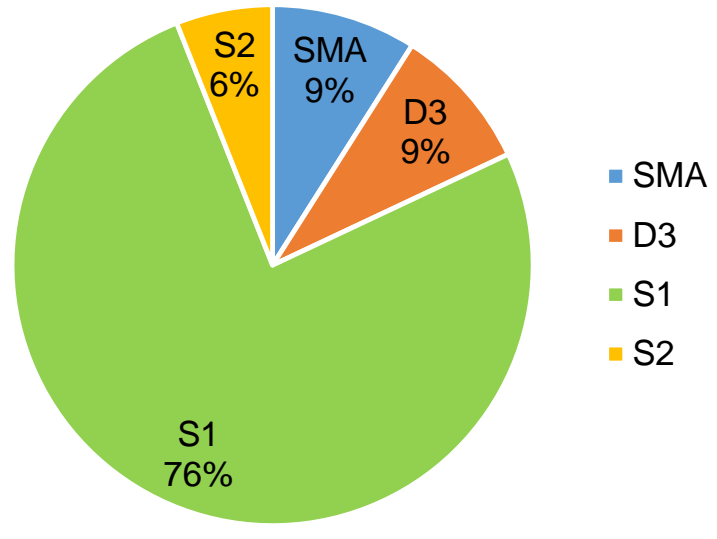

Sumber: Pengumpulan data primer

Gambar 2. Tabulasi Data Tingkat Pendidikan Responden

\section{Pengalaman Responden}

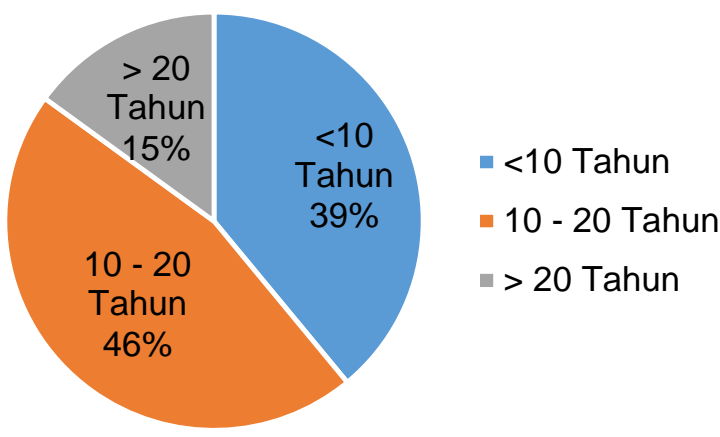

Sumber: Pengumpulan data primer

Gambar 3. Tabulasi Data Pengalaman Responden di Bidang Konstruksi

Untuk menguji apakah instrument pengukuran (kuesioner) pada penelitian ini valid, reliable atau tidak, maka dilakukan analisis validitas dan reliabilitas dengan menggunakan Alpha Cronbach sebagai koefisien reabilitasnya. Hasil analisis reabilitas dapat dilihat pada Tabel 5 dan 6.

Analisis dalam penelitian ini ialah menggunakan metode regresi linear sederhana pada program SPSS v.24, yaitu untuk menganalisis pengaruh produktivitas tenaga kerja terhadap kinerja waktu proyek. Hasil regresi linear sederhana dapat dilihat pada Tabel 7, 8 dan 9.

Tabel 5. Nilai Koefisien Alpha Cronbach

\begin{tabular}{|c|c|c|}
\hline \multicolumn{3}{|c|}{ Reliability Statistics } \\
\hline Cronbach's Alpha & $\begin{array}{l}\text { Cronbach's Alpha } \\
\text { Based on } \\
\text { Standardized Items }\end{array}$ & $\mathrm{N}$ of Items \\
\hline ,896 & ,897 & 16 \\
\hline
\end{tabular}

Tabel 6. Nilai Item-Total Statistic Analisis Reabilitas

\begin{tabular}{l|c|c|r|r|r}
\hline \multicolumn{7}{c|}{ Item-Total Statistics } \\
\hline & $\begin{array}{c}\text { Scale } \\
\text { Item if } \\
\text { Deleted }\end{array}$ & $\begin{array}{c}\text { Scale } \\
\text { Variance } \\
\text { if Item } \\
\text { Deleted }\end{array}$ & $\begin{array}{c}\text { Corrected } \\
\text { Item-Total } \\
\text { Correlation }\end{array}$ & $\begin{array}{c}\text { Squared } \\
\text { Multiple } \\
\text { Correlation }\end{array}$ & $\begin{array}{c}\text { Cronbach's } \\
\text { Alpha if } \\
\text { Item } \\
\text { Deleted }\end{array}$ \\
\hline D & 51,7576 & 74,502 &, 374 &, 687 &, 896 \\
\hline x1 & 49,3333 & 73,042 &, 410 &, 489 &, 895 \\
\hline x2 & 49,2424 & 70,627 &, 686 &, 866 &, 885 \\
\hline x3 & 49,4242 & 68,502 &, 631 &, 935 &, 887 \\
\hline x4 & 49,8182 & 70,778 &, 611 &, 912 &, 887 \\
\hline x5 & 50,2727 & 72,830 &, 535 &, 767 &, 890 \\
\hline x6 & 50,3636 & 72,864 &, 524 &, 843 &, 891 \\
\hline x7 & 50,5455 & 67,068 &, 622 &, 950 &, 888 \\
\hline x8 & 50,1515 & 71,633 &, 520 &, 942 &, 891 \\
\hline x9 & 50,1515 & 74,133 &, 440 &, 667 &, 893 \\
\hline x10 & 49,4242 & 68,877 &, 733 &, 962 &, 883 \\
\hline x11 & 49,7273 & 69,830 &, 707 &, 771 &, 884 \\
\hline x12 & 49,6667 & 71,167 &, 612 &, 919 &, 888 \\
\hline
\end{tabular}




\begin{tabular}{l|l|l|l|l|r}
\hline x13 & 49,5152 & 75,508 &, 457 &, 961 &, 893 \\
\hline x14 & 49,7576 & 69,252 &, 613 &, 775 &, 887 \\
\hline x15 & 49,4848 & 74,633 &, 507 &, 959 &, 892 \\
\hline
\end{tabular}

Sumber: Output data primer (SPSS v.24)

Nilai pada kolom Corrected Item-Total Correlation di Tabel 6 merupakan nilai korelasi yang didapatkan, kemudian dibandingankan dengan nilai $r$ tabel sebesar 0,334 . Dari hasil analisis didapat seluruh butir pertanyaan dari $x 1$ - x15 nilainya kurang dari 0,334, maka dapat disimpulkan bahwa butir instrumen tersebut valid.

Pada Tabel 5 dapat dilihat bahwa nilai koefisien Alpha Cronbach sebesar 0,896 . Nilai Alpha Cronbach ini jelas berada di atas batas minimal, yaitu 0,70 . Sehingga dapat disimpulkan bahwa skala pengukuran produktivitas tenaga kerja terhadap kinerja waktu proyek mempunyai reabilitas yang baik.

Nilai pada kolom Cronbach's Alpha if Item Deleted di Tabel 6 menunjukkan nilai koefisien Alpha Cronbach pada kolom Alpha if Deleted lebih kecil dari nilai Alpha Cronbach keseluruhan skala pengukuran, yaitu 0,896. Maka tidak ada butir pertanyaan yang dihapus atau direvisi.

Tabel 7. Model Summary Analisis Regresi

\begin{tabular}{ll|r|r|r}
\hline \multicolumn{5}{c}{ Model Summary } \\
\hline Model & $\mathrm{R}$ & R Square & $\begin{array}{c}\text { Adjusted R } \\
\text { Square }\end{array}$ & $\begin{array}{c}\text { Std. Error of } \\
\text { the Estimate }\end{array}$ \\
\hline 1 &, $370^{\mathrm{a}}$ &, 137 &, 109 &, 821 \\
\hline
\end{tabular}

a. Predictors: (Constant), Produktivitas Tenaga Kerja

Sumber: Output data primer (SPSS v.24)

Nilai $R^{2}$ ( $R$ square) 0,137 dari Tabel 7 menunjukkan bahwa $13,7 \%$ dari kinerja waktu proyek dapat dijelaskan oleh perubahan dalam variabel produktivitas tenaga kerja, sedangkan sisanya dijelaskan oleh sebab-sebab yang lain.

Tabel 8. Anova Analisis Regresi

\begin{tabular}{|c|c|c|c|c|c|c|}
\hline \multicolumn{7}{|c|}{ ANOVA $^{\mathrm{a}}$} \\
\hline \multicolumn{2}{|c|}{ Model } & $\begin{array}{l}\text { Sum of } \\
\text { Squares }\end{array}$ & df & $\begin{array}{c}\text { Mean } \\
\text { Square }\end{array}$ & $\mathrm{F}$ & Sig. \\
\hline \multirow[t]{3}{*}{$\overline{1}$} & Regression & 3,325 & 1 & 3,325 & 4,927 & $.034^{\mathrm{D}}$ \\
\hline & Residual & 20,918 & 31 & 675, & & \\
\hline & Total & 24,242 & 32 & & & \\
\hline
\end{tabular}

a. Dependent Variable: Kinerja Waktu Proyek

b. Predictors: (Constant), Produktivitas Tenaga Kerja

Sumber: Output data primer (SPSS v.24)

Pada tabel Anova (Tabel 8) mengindikasikan bahwa regresi secara statistik sangat signifikan dengan nilai $F=4,927$ untuk derajat kebebasan $k=1$ dan $n-k-1$ $=31$ dan $P$-value $=0,034$ yang lebih kecil dari $\alpha=$ 0,05 . Uji $F$ menguji secara serentak hipotesis $\mathrm{H}_{0}: \beta_{1}=$ $\beta_{2}=\beta_{3}=\ldots=\beta_{\mathrm{k}}=0$ terhadap $\mathrm{H}_{1}$ : tidak semua $\beta_{\mathrm{i}}, \mathrm{i}=1$, $2, \ldots, k$ sama dengan nol. Tetapi karena pada regresi sederhana hanya ada satu $\beta_{1}$, maka pengujian hanya dilakukan untuk $\mathrm{H}_{0}: \beta_{1}=0$ terhadap $\mathrm{H}_{1}: \beta_{1} \neq 0$. Dari
Tabel 8 jelas sekali terlihat bahwa $\mathrm{H}_{0}$ ditolak karena $P$ value $=0,034$ lebih kecil dari $\alpha=0,05$.

Tabel 9. Pemodelan Regresi

\begin{tabular}{|c|c|c|c|c|c|c|}
\hline \multicolumn{7}{|c|}{ Coefficients $^{\mathrm{a}}$} \\
\hline \multirow{2}{*}{\multicolumn{2}{|c|}{ Model }} & \multicolumn{2}{|c|}{$\begin{array}{c}\text { Unstandardized } \\
\text { Coefficients }\end{array}$} & \multirow{2}{*}{$\begin{array}{c}\text { Standardized } \\
\text { Coefficients } \\
\text { Beta }\end{array}$} & \multirow[b]{2}{*}{$\mathrm{t}$} & \multirow[b]{2}{*}{ Sig. } \\
\hline & & B & $\begin{array}{l}\text { Std. } \\
\text { Error }\end{array}$ & & & \\
\hline 1 & (Constant) &,- 363 & 845 & &,- 430 & 670 \\
\hline & $\begin{array}{l}\text { Produktivitas } \\
\text { Tenaga Kerja }\end{array}$ & ,556 & ,251 & ,370 & 2,220 & ,034 \\
\hline
\end{tabular}

a. Dependent Variable: Kinerja Waktu Proyek

Sumber: Output data primer (SPSS v.24)

Berdasarkan Tabel 9, persamaan garis regresi menggunakan metode kuadrat terkecil (least squares method) yang didapat adalah:

$y=-0,363+0,556 x$

dimana:

$y=$ kinerja waktu proyek

$\mathrm{x}=$ produktivitas tenaga kerja

Untuk menguji signifikansi masing-masing koefisien regresi digunakan uji statistik $t$. Untuk menguji $\mathrm{H}_{0}: \beta_{1}=$ 0 terhadap $\mathrm{H}_{1}: \beta_{1} \neq 0$ dari output SPSS didapat nilai uji- $t$ dengan nilai $t=-0,430$ dengan derajat kebebasan $n-2=33-2=31$ dan $P-$ value $=0,034$. Hal ini merupakan bukti kuat penolakan $\mathrm{H}_{0}: \beta_{1}=0$, karena $P$ - value $=0,034$ lebih kecil dari $\alpha=0,05$.

Berdasarkan hasil pengujian hipotesis di atas, maka pengembangan hipotesis sebagai pengambilan keputusan berdasarkan $P$ - value 0,05 atau $5 \%$ adalah sebagai berikut:

\section{Hipotesis:}

$\mathrm{H}_{0}$ : Produktivitas tenaga kerja tidak berpengaruh terhadap kinerja waktu proyek

$H_{1}$ : Produktivitas tenaga kerja berpengaruh terhadap kinerja waktu proyek

Berdasarkan Tabel 7, diperoleh nilai $R$ square 0,137 menunjukkan bahwa $13,7 \%$ dari kinerja waktu proyek dapat dijelaskan oleh perubahan dalam variabel produktivitas tenaga kerja, sedangkan sisanya dijelaskan oleh sebab-sebab yang lain. Sebab-sebab lain yang mungkin dapat menjelaskan kinerja waktu proyek misalnya faktor biaya, material, peralatan, metode konstruksi, atau teknologi.

Berdasarkan Tabel 9 didapatkan nilai konstanta sebesar $-0,363$ yang berarti bahwa jika ada penurunan produktivitas tenaga kerja maka kinerja waktu proyeknya adalah sebesar $-0,363 \%$. Koefisien regresi $x$ sebesar 0,556 menyatakan bahwa setiap terjadi kenaikan produktivitas tenaga kerja yang disebabkan oleh variabel $x$ sebesar $1 \%$, maka kinerja waktu proyek akan mengalami kenaikan sebesar $0,556 \%$. Untuk nilai signifikansi pada Tabel 9 adalah sebesar 0,034. Oleh karena probabilitas lebih kecil dari 0,05 maka $\mathrm{H}_{1}$ diterima, yaitu produktivitas tenaga kerja berpengaruh terhadap kinerja waktu proyek. 


\section{KESIMPULAN}

Dalam penelitian ini didapatkan simpulan bahwa produktivitas tenaga kerja berpengaruh secara signifikan terhadap kinerja waktu proyek. Indikatorindikator yang digunakan dalam setiap kelompok, yaitu man group factor, leadership group factor, time group factor, materials/tools group factor, supervision group factor dan safety group factor berpengaruh secara signifikan terhadap kinerja waktu proyek. Misalnya salah satu indikator dalam safety factor, yaitu minimnya peralatan safety berpengaruh terhadap kinerja waktu proyek. Minimnya peralatan safety pada pekerjaan konstruksi gedung bertingkat akan sangat mungkin berakibat pada terlambatnya suatu kegiatan, karena tenaga kerja mungkin merasa tidak terjamin keselamatannya, sehingga secara tidak langsung berimplikasi terhadap menurunnya efektifitas tenaga kerja. Begitupun dengan faktor-faktor produktivitas dalam kelompok lainnya, mempunyai pengaruh terhadap kinerja waktu proyek. Dengan kata lain, jika semakin tinggi produktivitas tenaga kerja, maka semakin singkat pula waktu yang diperlukan dalam penyelesaian suatu kegiatan. Sehingga waktu penyelesaian proyek dapat dapat lebih cepat dari waktu normal, atau sebaliknya.

Produktivitas tenaga kerja merupakan hal yang penting dalam suatu proyek konstruksi, misalnya bangunan bertingkat. Produktivitas tenaga kerja erat kaitannya dengan kinerja waktu proyek. Dalam waktu kerja normal, jika semakin tinggi produktivitas tenaga kerja, maka semakin singkat pula waktu yang diperlukan dalam penyelesaian suatu kegiatan. Sehingga waktu penyelesaian proyek dapat lebih cepat dari waktu normal. Faktor manusia menjadi penentu untuk mencapai tingkat produktivitas yang ditetapkan. Lebih jelas dapat disebut bahwa tukanglah penentu kinerja tim proyek secara keseluruhan tanpa mengesampingkan peran faktor yang lain. Untuk mendapatkan tingkat produktivitas yang diinginkan dan meminimalkan segala risiko yang mungkin terjadi serta mengutamakan keselamatan dan kesehatan kerja, para pemimpin harus memahami kemampuan dan keterbatasan yang diakibatkan oleh kondisi lokasi proyek.

Dari penelitian yang sudah dilakukan, terlihat bahwa pengaruh produktivitas tenaga kerja hanya difokuskan terhadap kinerja waktu proyek saja. Pada penelitian selanjutnya sebaiknya dilakukan penelitian yang lebih meluas, misalnya, tidak hanya pengaruh produktivitas tenaga kerja terhadap kinerja waktu proyek saja, tetapi dapat dilakukan analisis pengaruhnya terhadap biaya.

\section{UCAPAN TERIMA KASIH}

Penulis mengucapkan terima kasih sebesar-besarnya untuk semua pihak yang membantu dalam penyelesaian penulisan ini, terutama kepada para responden pada perusahaan konstruksi yang tersebar di beberapa wilayah Jabodetabek yang sudah meluangkan waktunya dalam pengisian kuesioner.

\section{REFERENSI}

Abdul Kadir, M.R., Lee, W.P., Jaafar, M.S., Sapuan, S.M., Ali, A.A.A. (2005). Factors Affecting Construction Labour Productivity for Malaysian Residential Projects. Structural Survey, Vol. 23 Issue: 1, pp.42-54.

Alinaitwe, Henry Mwanaki., Mwakali, Jackson A., Hansson, Bengt. (2007). Factors Affecting The Productivity of Building Craftsmen - Studies of Uganda. Journal of Civil Engineering and Management, Vol. XIII, No. 3: 169- 176.

Bekr, Ghanim A. (2016). Study of Significant Factors Affecting Labor Productivity at Construction Sites in Jordan: Site Survey. Journal of Engineering Technology (JET), Vol. 4 No. 1, pp. $92-97$.

Enshassi, Adnan., Mohamed, Sherif., Mustafa, Ziad Abu., Mayer, Peter Eduard. (2007). Factors Affecting Labour Productivity in Building Projects in the Gaza Strip. Journal of Civil Engineering and Management, Vol. XIII, No. 4: $245-254$.

Ervianto, Wulfram I. (2005). Manajemen Proyek Konstruksi (Edisi Revisi), Andi.

Hanafi, Mohd Hanizun., Khalid, Abd. Ghani., Razak, Arman Abdul., Abdullah, Shardy. (2010). Main Factors Influencing Labour Productivity of the Installation of On-Site Prefabricated Components. International Journal of Academic Research, Vol. 2, No. 6, Part I.

Margareth, Lelly., Simanjuntak, Manlian Ronald A. (2010). Pengaruh Produktivitas Tenaga Kerja Terhadap Kinerja Proyek Bangunan Tinggi di DKI Jakarta. Konferensi Nasional Teknik Sipil 4 (KoNTekS 4).

Muzayanah, Yannu. 2008. Pemodelan Proporsi Sumber Daya Proyek Konstruksi. Tesis Program Pasca Sarjana Universitas Diponegoro. Semarang. $136 \mathrm{hlm}$.

Riantini, Leni Sagita., Trigunarsyah, Bambang., Abidin, Ismeth., Latief, Yusuf. (2005). Penentuan Peringkat Faktor Risiko dalam Rekrutmen Tenaga Kerja yang Mempengaruhi Biaya Tenaga Kerja pada Proyek. Jurnal Teknik Sipil, Vol. 12 No. 3.

Santoso, Singgih, 2005. Menguasai Statistik di Era Informasi dengan SPSS 12, Elex Media Komputindo, Jakarta.

Soeharto, Iman (1997). Manajemen Proyek: dari Konseptual sampai Operasional. Erlangga.

Soekiman, A., K. S. Pribadi, B. W. Soemardi, R. D. Wirahadikusumah. (2011). Factors Relating to Labor Productivity Affecting the Project Schedule Performance in Indonesia. Procedia Engineering 14 (2011), 865 - 873.

Thomas, Anu V., Sudhakumar, J. (2014). Factor Influencing Construction Labour Productivity: An India Case Study. Journal of Construction in Developing Countries, 19(1), 53-68.

Uyanto, Stanislaus S .(2006). Pedoman Analisis Data dengan SPSS. Graha IImu. 
Widayat, Wahyu. (2007). Faktor-Faktor Risiko yang Menyebabkan Rendahnya Produktivitas Tenaga Kerja Terampil yang Berpengaruh terhadap Keterlambatan Waktu Proyek. Tesis Program Studi Teknik Sipil Universitas Indonesia. Depok. $108 \mathrm{hlm}$. 
Halaman ini sengaja dikosongkan 